\title{
EFEITO DA TEMPERATURA E DO CLORETO DE SÓDIO (SALGA SECA) SOBRE A VIABILIDADE DO CYSTICERCUS CELLULOSAE EM SEGMENTOS DE CARNE SUINA DE DIFERENTES ESPESSURAS.
}

\author{
Raphael Valentino RICCETTI * \\ José Cezar PANETTA * \\ Omar Jaques Marzagão BARBUTO**
}

RFMV-A/14

RICCETTI, R.V.; PANETTA,J.C.; BARBUTO, O.J.M. Efeito simultâneo da temperatura e do cloreto de sódio (salga seca) sobre a viabilidade do Cysticercus cellulosae, em segmentos de carne suína de diferentes espessuras. Rev. Fac. Med. vet. Univ. S.Paulo, 14(1): 113-122, 1977.

RESUMO: Foi avaliado o poder de inativaçốo do cloreto de sódio, sobre o Cysticercus cellulosae, contido em cortes de carne suina de várias espessuras. Pamalelamente, foi estudado o efeito simultâneo da temperatura de refrigeração e da salga. Após a análise dos resultados concluiu-se pela eficiente at uação do cloreto de sódio sôbre o Cysticercus cellulosae, na forma de salga seca, em peças de até 6 .cm de espessura, desaconselhando-se o emprego simultâneo da saga e refrigeração.

UNITERMOS: Taenia solium *; Cisticercose, suinos *; Carne cisticercótica *.

\section{INTRODUÇÃO}

As teniases e as cisticercoses animal e humana, continuam representando um sério problema de ordem médico-social e econômica.

Os vários pontos que devem ser abordados com intuito de diminuir os índices de incidência desta zoonose pressupõem uma solução a longo prazo.

Dentre os vários enfoques que devem merecer atenção situa-se como de fundamental importância o elo do ciclo representado pela ingestão de carnes contaminadas.

0 tratamento de carnes cisticercóticas, condiciona dois aspectos altamente relevantes, primeiramente sob o ponto de vista eco- nômico, representado por tratamento prático, eficiente e não oneroso; em segundo lugar, problemas atinentes ao aspecto sanitário, garantindo ao consumidor uma completa inocuidade do alimento.

Realçando, sobremaneira, a importância desta problemática, ABDUSSALAM ${ }^{1}$, na VII Reunião Interamericana sobre o controle da Febre Aftosa e outras zoonoses, realizada em Trinidad Tobago (1975), afirma: "los métodos actuales para destruir los cisticercos en la carne (congelación, ebullición, etc.) son caros y uno de ellos (la ebullición) altera radicalmente el alimento, Se ha propuesto el empleo de radiaciones ionizantes. Es urgente dessarrollar um métedo barato $\mathrm{y}$ de fácil aplicación".

* Professor Assistente Doutor

* Professor Livie-Docente

Departamento de Medicina Veterinária Preventiva e Saúde Animal da Faculdade de Medicina Veterinária e Zootecnia da USP. 
Imbuidos dessa mesma preocupação os autores objetivam o encontro de uma solução simples e exequível economicamente, concernente ao tratamento da carne suína contaminada, para que, a um tempo nâo houvesse risco à saúde do consumidor e não se disperdiçasse totalmente a proteina de elevado valor biológico contida na carne.

A salga como tratamento de carne cisticercótica é assunto amplamente discutido em todo o mundo, admitida pela legislação vigente em alguns paises (França ${ }^{12}$, Itália ${ }^{4}$, México $^{12}, B^{4}$ sail $^{2}$ ) não o sendo pela de outros $\left(\right.$ EUA $^{4}$, Bélgica $^{12}$, Espanha ${ }^{8}$ ), provocando diferentes e acirradas posições quanto ao seu valor.

SCHMID ${ }^{9}$, THORTON ${ }^{12}$, SCHNAAS ${ }^{10}$, TRAWINSKI ${ }^{13}$. TALAVERA ${ }^{1}$ i $^{2}$ PELEGRINI ${ }^{5}$ EDELMAN $^{3}$, citam a salga como método adequado na inativaçăo de Cysticercus cellulosae, sem no entanto, fazerem qualquer referência quanto às espessuras das peças a serem tratadas.

Não existindo qualquer trabalho científico específico que possa sustentar qualquer uma das correntes objetiva-se neste trabalho, evidenciar-se a atuaçao do $\mathrm{NaCl}$ como método simples, econômico e eficiente, no tratamento de segmentos cárneos de suínos infestados, correlacionando-se espessura da carne, salga e temperatura adequada.

\section{MATERIAL E MÉTODOS}

- Chegadas ao laboratório, as carcaças contaminadas, eram segmentadas, separando-se principaltiente os músculos biceps femural, quadriceps femural, semitendinoso e subescapular, orientando-se o retalhamento, de sorte a obter-se peças de espessuras que variavam de 1 a $6 \mathrm{~cm}$ e de 20 a $30 \mathrm{~cm}$ de comprimento (Fig. nQ 1).

Em seguida procedia-se a: a) pesagem das peças; b) salga com cloreto de sódio (salga seca) na proporção de duas partes da carne para uma de sal; c) colocação das peças em cubas plásticas e submetidas a duas temperaturas, ambiente $\left( \pm 22^{\circ} \mathrm{C}\right)$ e de refrigeração $\left(4^{\circ} \mathrm{C}\right)$. (Fig. nọ 2).
0 sal era fornecido pelo próprio frigorífico, usado após a verificaçăo da quantidade de nitrito existente.

A cada 24 horas sob as temperaturas citadas, recolhiam-se de cada peça 20 cistos profundos.

Os cistos considerados superficiais não foram coletados, ficou amplamente demonstrado em trabalho anterior ${ }^{7}$ a inativação dos mesmos em 24 horas de atuação do sal.

Para obtenção dos cistos profundos, procedia-se da seguinte maneira: cada segmento cárneo de espessura de 1 a $6 \mathrm{~cm} \mathrm{e}$ de comprimento em torno de 20 a $30 \mathrm{~cm}$, era seccionado a uma distância da borda, o equivalente à metade da espessura (do respectivo segmento), media-se o centro do corte e colocava-se uma linha preta no $20 \mathrm{em}$ toda a extensão do mesmo coletando-se os cistos em contacto com a linha, respeitando-se um afastamento das laterais equivalente à metade da espessura (Fig. no 3).

Após a retirada dos cistos, a região do corte era salgada e a peça recolocada na cuba para análise posterior.

Os cistos recolhidos eram colocados em líquido próprio para evaginação ${ }^{6}$ e levados para estufa a $45^{\circ} \mathrm{C}$.

Foram usadas para esse fim 30 carcaças de suínos, de cada carcaça conseguimos 12 peças, duplicata das 6 espessuras.

\section{RESULTADOS}

Os resultados obtidos são apresentados nas Tabelas nos 1, 2 e 3.

A Tabela no 1 resume os dados em número de cistos evaginados, colhidos diariamente, nas várias espessuras (l a $6 \mathrm{~cm}$ ), submetido às temperaturas $\varepsilon$ ambiente $\left( \pm 22^{\circ} \mathrm{C}\right)$ e de refrigeração $\left(4^{\circ} \mathrm{C}\right)$, correspondendo à analise de carnes provenientes de 30 carcaças. Tem por finalidade demonstrar a eficiência da atuação do cloreto de sódio na inativação dos cistos de Cysticercus cellulosae, em carnes de varias espessuras.

A Tabela no 2 mostra-nos a soma dds cistos evaginados nas várias espessuras durant te os dias de atuaçăo do cloreto de sódio, em carnes contaminadas submetidas a duas tem- 
FIGURA 1 - Segmentos cárneos de suinos, de várias espessuras, antes da aplicagaio do sal.

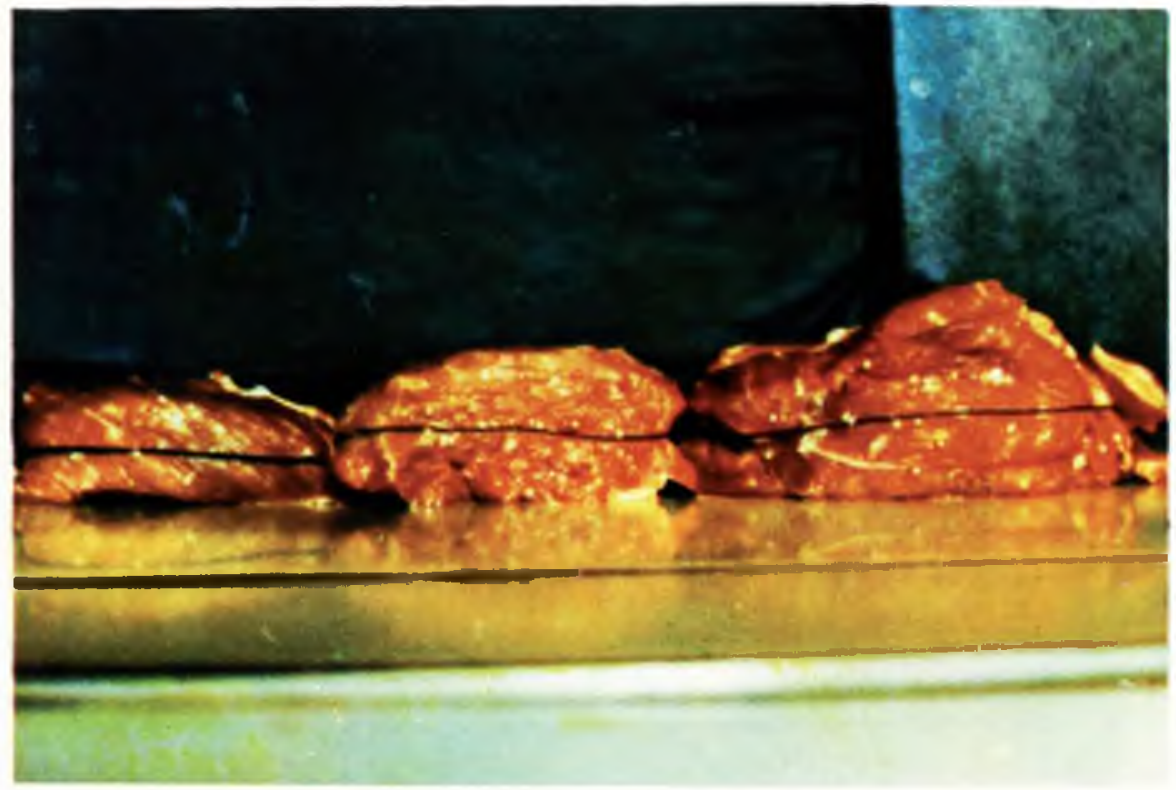

FIGURA 2 - Segmentos cárneos de várias espessuras, salgados e colocados em cubas plásticas à temperatura ambiente.

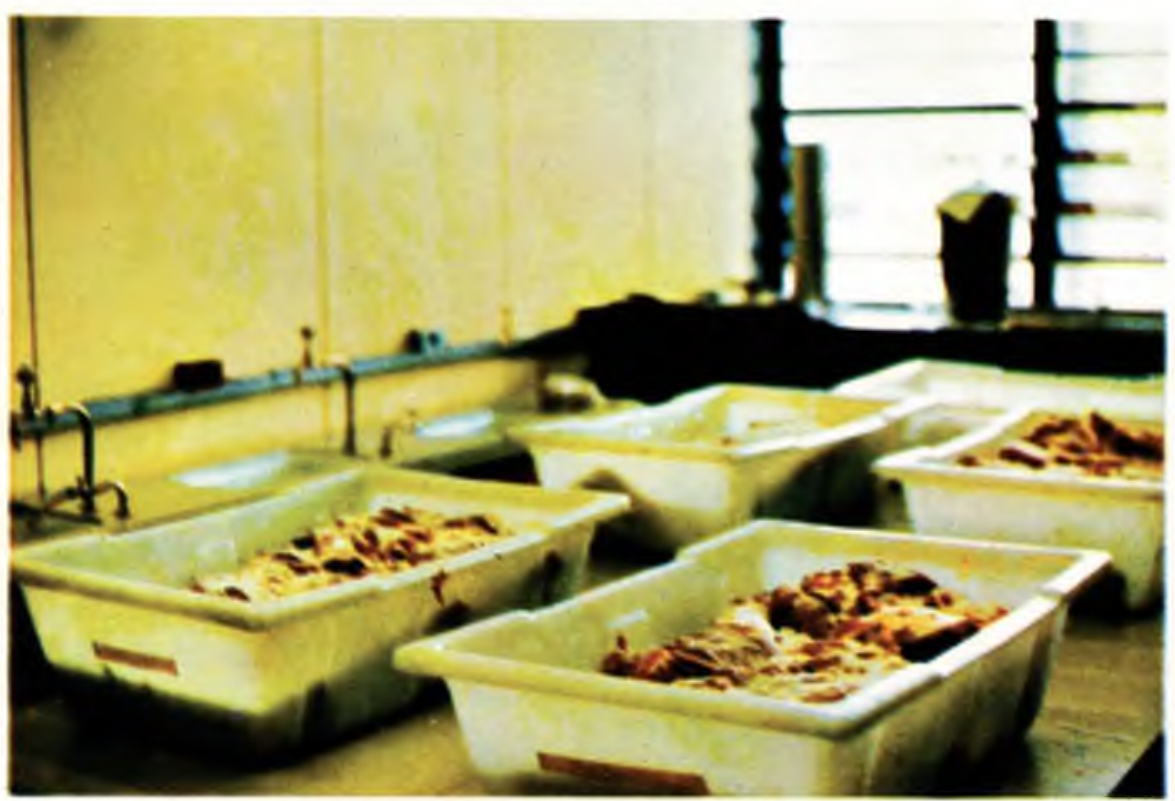


FICURA 3 - Detalhes de segmentos cárneos de suínos infestados, notando-se a linha mediana.

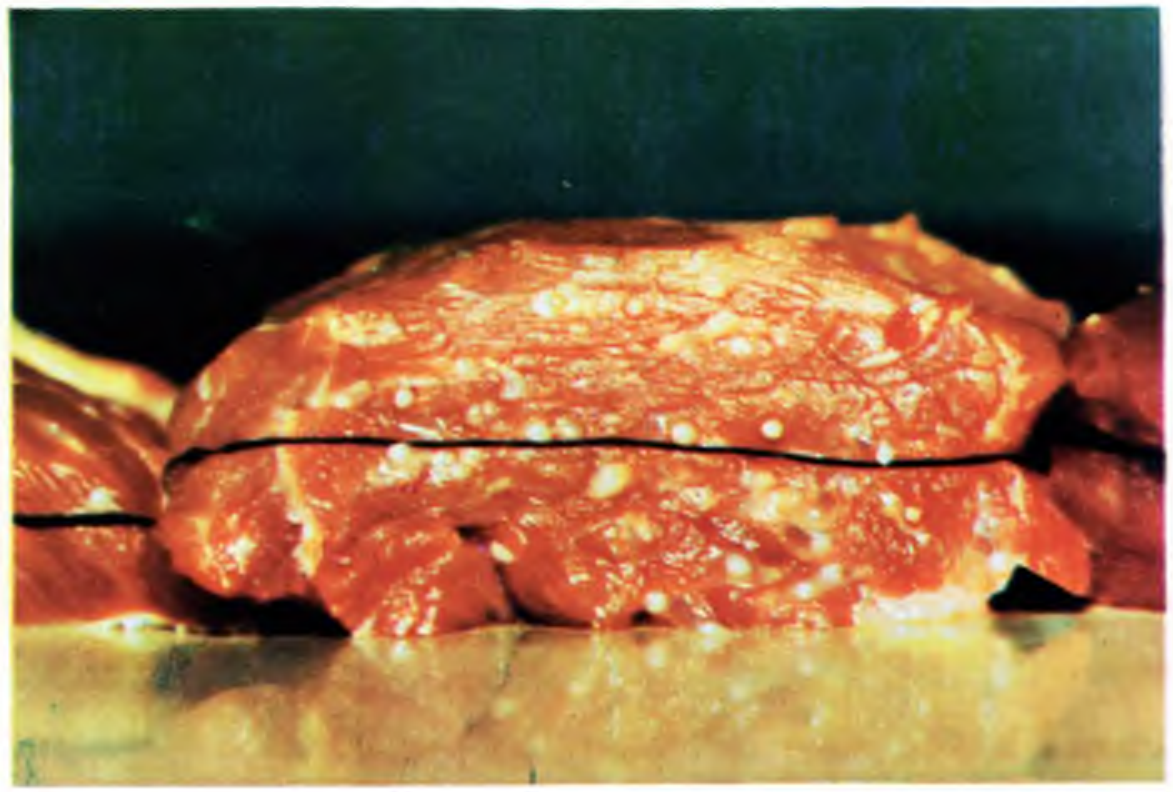




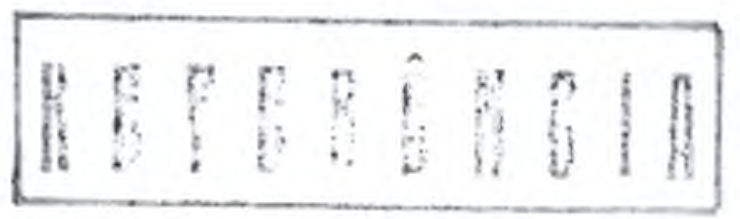

TABELA I - Totais de cistos euaginados com salga seca, segundo a espessura, temperat ura e dias de observação.

\begin{tabular}{|c|c|c|c|c|c|c|c|c|c|c|c|c|}
\hline \multirow{2}{*}{ Dias } & \multicolumn{6}{|c|}{ Ambiente $\left( \pm 22^{\circ} \mathrm{C}\right)$} & \multicolumn{5}{|c|}{ Refrigeração $\left(4^{\circ} \mathrm{C}\right)$} & \multirow[b]{2}{*}{$\begin{array}{c}6 \\
\mathrm{~cm}\end{array}$} \\
\hline & $\underset{c m}{I}$ & $\begin{array}{c}2 \\
c m\end{array}$ & $\begin{array}{c}3 \\
c m\end{array}$ & $\begin{array}{c}4 \\
c m\end{array}$ & $\begin{array}{c}5 \\
c m\end{array}$ & $\begin{array}{c}6 \\
\mathrm{~cm}\end{array}$ & $\underset{c m}{I}$ & $\begin{array}{c}2 \\
\mathbf{c m}\end{array}$ & $\begin{array}{c}3 \\
c m\end{array}$ & $\begin{array}{c}4 \\
\mathrm{~cm}\end{array}$ & $\begin{array}{c}5 \\
c m\end{array}$ & \\
\hline 1 & 74 & 395 & 466 & 527 & 569 & 577 & 365 & 541 & 556 & 593 & 595 & 599 \\
\hline 2 & - & 150 & 313 & 419 & 480 & 518 & 139 & 405 & 509 & 557 & 578 & 584 \\
\hline 3 & - & - & 129 & 248 & 358 & 422 & - & 299 & 436 & 520 & 568 & 578 \\
\hline 4 & - & - & - & 102 & 218 & 291 & - & 198 & 391 & 442 & 519 & 556 \\
\hline 5 & - & - & - & - & 105 & 172 & - & 98 & 314 & 403 & 462 & 517 \\
\hline 6 & - & - & - & - & - & 76 & - & - & 230 & 357 & 387 & 470 \\
\hline 7 & - & - & - & - & - & - & - & - & 153 & 288 & 326 & 403 \\
\hline 8 & - & - & - & - & - & - & - & - & 79 & 214 & 286 & 361 \\
\hline 9 & - & - & - & - & - & - & - & - & - & 157 & 238 & 299 \\
\hline 10 & - & - & - & - & - & - & - & - & - & 100 & 209 & 261 \\
\hline 11 & - & - & - & - & - & - & - & - & - & 38 & 147 & 218 \\
\hline 12 & - & - & - & - & - & - & - & - & - & - & 108 & 166 \\
\hline 13 & - & - & - & - & - & - & - & - & - & - & 69 & 117 \\
\hline 14 & - & - & - & - & - & - & - & - & - & - & - & 69 \\
\hline 15 & - & - & - & - & - & - & - & - & - & - & - & 2 \\
\hline 16 & - & - & - & - & - & - & - & - & - & - & - & - \\
\hline 17 & - & - & - & - & - & - & - & - & - & - & - & - \\
\hline
\end{tabular}


TABELA 2 - Totais de cistos evaginados por dia, nas 30 carcaças, nas uárias espessuras $(1$ a $6 \mathrm{~cm})$.

\begin{tabular}{|c|c|c|c|c|}
\hline Dias & $\begin{array}{l}\text { No de cistos eua- } \\
\text { ginados em peças } \\
\text { salgadas - temp. } \\
\text { ambiente }\end{array}$ & $\%$ & $\begin{array}{c}\text { No de cistos evagi- } \\
\text { nados em peças sal- } \\
\text { gadas e refrigeradas } \\
\text { a } 40 \text { C }\end{array}$ & $\%$ \\
\hline$I$ & 2.608 & 72.0 & 3.249 & 90.2 \\
\hline 2 & 1.880 & 52.2 & 2.772 & 77.0 \\
\hline 3 & 1.151 & 31.0 & 2.401 & 66.6 \\
\hline 4 & 611 & 16.9 & 2.106 & 58.1 \\
\hline 5 & 277 & 7.8 & 1.794 & 49.8 \\
\hline 6 & 76 & 2.1 & 1.444 & 40.1 \\
\hline 7 & - & - & 1.170 & 32.5 \\
\hline 8 & - & - & 940 & 26.1 \\
\hline 9 & - & - & 694 & 19.2 \\
\hline 10 & - & - & 570 & 15.8 \\
\hline 11 & - & - & 403 & 11.1 \\
\hline 12 & - & - & 274 & 7.6 \\
\hline 13 & - & - & 186 & 5.1 \\
\hline 14 & - & - & 69 & 1.9 \\
\hline 15 & - & - & 2 & 0.05 \\
\hline 16 & - & - & - & - \\
\hline 17 & - & - & - & - \\
\hline
\end{tabular}


TABELA 3 - Número de cistos evaginados sobre um total de 20 cistos, coletados de pegas salgadas, segundo espessura, temperatura e dias de observação.

\begin{tabular}{|c|c|c|c|c|c|c|c|c|c|c|c|c|}
\hline \multirow{2}{*}{ Dias Espessura } & \multicolumn{6}{|c|}{ Ambiente $\left( \pm 22^{\circ} \mathrm{C}\right)$} & \multicolumn{6}{|c|}{ Refrigeração $\left(4^{\circ} \mathrm{C}\right)$} \\
\hline & $\underset{c m}{l}$ & $\underset{c m}{2}$ & $\begin{array}{c}3 \\
c m\end{array}$ & $\begin{array}{c}4 \\
\mathrm{~cm}\end{array}$ & $\underset{c m}{S}$ & $\begin{array}{c}6 \\
\mathrm{~cm}\end{array}$ & $\stackrel{l}{c m}$ & $\underset{c m}{2}$ & $\begin{array}{c}3 \\
c m\end{array}$ & $\begin{array}{c}4 \\
\mathrm{~cm}\end{array}$ & $\underset{c m}{5}$ & $\begin{array}{c}6 \\
\mathrm{~cm}\end{array}$ \\
\hline I & I & 16 & 18 & 20 & 20 & 20 & 17 & 20 & 20 & 20 & 20 & 20 \\
\hline 2 & - & 8 & 14 & 19 & 20 & 19 & 6 & 13 & 17 & 20 & 19 & 20 \\
\hline 3 & - & - & 3 & 12 & 18 & 19 & - & 10 & 18 & 20 & 20 & 20 \\
\hline 4 & - & - & - & 2 & 10 & 17 & - & 8 & 20 & 19 & 20 & 20 \\
\hline 5 & - & - & - & - & $l$ & 3 & - & 3 & 18 & 20 & 20 & 20 \\
\hline 6 & - & - & - & - & - & 1 & - & - & 10 & 16 & 15 & 17 \\
\hline 7 & - & - & - & - & - & - & - & - & 8 & 12 & 13 & 16 \\
\hline 8 & - & - & - & - & - & - & - & - & 6 & 10 & 10 & 12 \\
\hline 9 & - & - & - & - & - & - & - & - & - & 6 & 10 & 13 \\
\hline 10 & - & - & - & - & - & - & - & - & - & 4 & 11 & 10 \\
\hline 11 & - & - & - & - & - & - & - & - & - & 3 & 7 & 9 \\
\hline 12 & - & - & - & - & - & - & - & - & - & - & 4 & 9 \\
\hline 1.3 & - & - & - & - & - & - & - & - & - & - & 2 & 5 \\
\hline 14 & - & - & - & - & - & - & - & - & - & - & - & 4 \\
\hline 15 & - & - & - & - & - & - & - & - & - & - & - & - \\
\hline 16 & - & - & - & - & - & - & - & - & - & - & $\rightarrow$ & - \\
\hline 17 & - & - & - & - & - & - & - & - & - & - & - & - \\
\hline
\end{tabular}

Rev. Fac. Med. vet. Zootec. Univ. S. Paulo, 14(1):113-122, 1977. 
peraturas ambiente $\left( \pm 22^{\circ} \mathrm{C}\right)$ e de refrigeração $\left(4^{\circ} \mathrm{C}\right)$.

A análise desta Tabela evidencia a interferência da temperatura sobre o método de tratamento (salga) no referente à inativação dos cistos.

A Tabela nọ 3 demonstra a atuação do cloreto de sódio no primeiro lote tratado, nas várias espessuras usadas e nas duas temperaturas.

A simples visualização das Tabelas nes 1 e 2, mostra a significante diferença da atuação do cloreto de sódio quando a carne contaminada salgada é deixada em temperatura ambiente e em refrigeração a $4^{\circ} \mathrm{C}$.

$\mathrm{Na}$ Tabela $\mathrm{n}: 2$, podemos verificar a diferença constante desde as primeiras 24 horas de atuação até o 15 \% dia.

O tratamento estatístico baseou-se na aplicação de teste de duas proporções. com aproximação pela distribuição normal, ao nível de rejeição de $1 \%$, SPIEGEL ${ }^{11}$. Mesmo ao nivel de rejeiçăo de $1 \%$, a diferença entre lotes nos 7 dias, apresentou-se significante, quando se utilizou o teste de 2 proporções, com aproximaçăo pela distribuição normal de probabilidades.

\section{COMENTÁRIOS}

Pela simples análise da Tabela nọ 3 , verifica-se que no primeiro dia de salga há diferente penetração do sal na massa cárnea, pois em temperatura ambiente na espessura de $1 \mathrm{~cm}$, dos 20 cistos coletados a essa profundidade, apenas I evaginou, enquanto que, no mesmo tempo, na mesma espessura, em temperatura de refrigeração, dos 20 cistos coletados, 17 evaginaram, pressupondo-se que nessa temperatura o sal não conseguiu penetrar totalmente.

No lote em refrigeração, a inativação completa dos cistos em carnes de $3 \mathrm{~cm}$ de espessura só se completou por volta do nono dia, pressupondo-se que o $\mathrm{NaCl}$ necessita do dobro de temperatura para inativação do Cysticercus cellulosae, quando a carne é colocada a $4^{\circ} \mathrm{C}$. No enfoque total do experimento, esta dedução se caracterizou com mais evidência pois foram necessários 7 dias para que o cloreto de sódio inativasse todos os cistos em todas as espessuras usadas ( 1 a 6 cm), enquanto que o mesmo só sconteceu nas peças em refrigeração por volta do 15 ? dia.

Pretendeu-se, ao se estudar o comportamento de um lote salgado, colocado em temperatura de refrigeração, estabelecer uma possível interferência da temperatura sobre a atuação do cloreto de sódio. Tal fato, torna-se perfeitamente demonstrado ao analisar-se os dados sumarizados na Tabela $n 91$, onde se faz um confronto do total de cistos evaginados no lote salgado e mantido à temperatura ambiente, frente a outro salgado $e$ colocado em refrigeração a $4^{\circ} \mathrm{C}$.

Observa-se, pela verificação nos dife. rentes dias após tratamento e em espessuras maiores, um aumento progressivo da atuação do sal, mas sempre proporcional reente mais lento na temperatura de $4^{\circ} \mathrm{C}$. Ao atingir o quarto dia no lote mantido em temperatura ambiente, houve ausência de evaginação na espessura de $3 \mathrm{~cm}$, fato este que referenda os achados de trabalho anterior? ${ }^{7}$. Por sua vez, no lote colocado em refrigeraçäo no mesmo periodo e mesma espessura observamos apenas uma discreta atuaçao do $\mathrm{NaCl}$ sobre os cistos.

Na Tabela n9 2, onde aparecem os totais de cistos evaginados, por dia, nas várias espessuras, temos um resultado seguro que nos permite afirmar a negativa interferência da temperatura baixa em carnes contaminadas salgadas.

No primeiro dia, já se nota uma significante diferença entre os cistos evaginados nos dois processos de tratamento.

Enquanto que nas peças solgadas em temperatura ambiente 2.608 evaginaram $(72,4 \%)$, no mesmo período nas peças salgadas e refrigeradas $3.249(90,2 \%)$ evaginaram, do total de 3.600 cistos usados para cada processo.

Nos cistos considerados profundos (abaixo da camada de tecido muscular) protegidos pela mesma, de acordo com a espessura, o frio retarda a penetração do sal por um mecanismo puramente físico, retardando simplesmente a sua ação. Este fenomeno juotifica desaconselhar-se totalmente a coloca. ção de peças contaminadas salgadas em temperatura de refrigeraçåo. 
Portanto, é acentuada a interferência da temperatura na penetração do sal $\mathrm{e}$, consequentemente, na atuação deste sobre os cistos.

Sabe-se, por outro lado que o $\mathrm{NaCl}$ usado adequadamente sob orientação e fiscalização veterinária, pode e deve ser considerado como um ótimo agente inativador do $C$. cellulosae: sua atuação é altamente significante na importante tarefa de tornar inócua ao consumidor as carnes contaminadas por larvas de $T$. solium

\section{CONCLUSŌES}

1 - Demonstrou-se a significante atuação do cloreto de sódio na forma de salga seca, na inativação de formas larvares de $T$. solium, em carnes de suínos até a espessura de $6 \mathrm{~cm}$;
2 - nos segmentos cárneos de espessura máxima de $6 \mathrm{~cm}$ em temperatura ambiente, o $\mathrm{NaCl}$ inativou completamente os cistos de $C$. cellulosae, no prazo de $?$ dias;

3 - nas carnes de espessura máxima de 6 $\mathrm{cm}$, o $\mathrm{NaCl}$, na forma de salga seca associada a temperatura $\left(4^{\circ} \mathrm{C}\right)$, a inativação total dos cistos deu.se no $15^{\circ}$. dia;

4 - a refrigeração usada, concomitantemente, com salga seca, exerce uma interferência negativa nesta última;

5 - desaconselha-se a prática de se colocar peças salgadas (salga seca) em temperatura de refrigeração $\left(4^{\circ} \mathrm{C}\right)$, pois neste caso o tempo necessário para a inativação dos cistos de $C$. cellulosae é retar. dado, sobremaneira.

\section{RFMV.A/ 14}

RICCETTI, R.V.; PANETTA, J.C.; BARBUTO, O.J.M. The effect of temperature/salt concentration upon the viability of Cysticercus cellulosae in swine meat fragments of different thickness. Rev. Fac. Med. vet. Zootec. Univ. S. Paulo, 14(1): 113.122, 1977.

SUMMARY: It was studied the action of sodium chloride in fragments larger than 3 centimeters of swine meat infected with C. cellulosae as well as the effect of both temperature of refrigeration and salt. The authors have concluded that the more efficient treatment was the use of dry sodium chloride at room temperature based on the fact that low temperature delayed the process of C. cellulosae killing.

\section{REFERĒNCIAS BIBLIOGRẢFICAS}

1 - ABDUSSALAM, M. El problema de la teniasis cisticeroosis. In: REUNION INTERAMERICANA SOBRE EL CONTROL DE LA FIEBRE AFTOSA Y OTRAS ZOONOSES, 7. . Puerto España, 1974. Annales. p.117-25 Washington, Organización Panamericana de la Salud, 1975. (Publicación Científica, 295).

2 - BRASIL. Leis e Decretos. Decteto n? 30.691 de 29/03/1952. Rio de Janeiro, Ministério da Agricultura, 1953.

3 - EDELMAN, R. Textbook of meat hygienne. 8.ed. Philadelphia, Lea \& Febiger, 1943. p.271-6.

4 - MANTOVANI, G. Inspezione degi ali- menti di origine animale. Torino, Unione Tipografica-Editrice Torinense, 1961. p.990-1011.

5 - PELlEGRINI, D. La profilassi della cisticercose bovina. Vet. Ital. 9(1):25-38, 1958

6 - RICCETTI, R.V. Estudo sobre a evaginação "in vitro" do Cysticercus cellulo. sae. Rev. Fac. Med. vet. Zootec. Univ. S.Poulo, 12:247-58, 1975.

7 - RICCETTI, R.V. Estudo sobre a atuçäo do cloreto de sódio na inativaçăo do Cysticercus cellulosae, em massas musculares de suínos naturalmente infectados. Rev. Fac. Med. vet. Zootec. Univ. S.Paulo, 12:259-68, 1975. 
8 - SANZ EGAÑA, C. Enciclopedia de la carne. Madrid, Espassa Calpe, 1948. p.893-7.

9 - SCHMID, G. Inspección "post-mortem" y dictamen sobre canales con infestación parasitaria. In: ORGANIZACION MUNDIAL DE LA SALUD. Higiene de la carne. genebra, 1959. p.233-52.

10 - SCHNAAS, G. Aspectos sanitários de la cisticercose. Gac. med. Méx. 92(12):1009-106, 1963.

11 - SPIEGEL, M.R. Estatística. Teoria da decisão estatística. Testes de hipótese e significância. s.L.p., Coleção Schaum, 1972.p.276
12 - TALAVERA, J. La cistecercose chez les animaux e chez l'homme et plus partillièrement la cysticercose cerébrale. Bull. Off, int. Epizoot. 48:584-604, 1957.

13 - THORTON, H. Compéndio de inspectio de carnes. Londres, Baillière Tindall and Cassel, 1969. p.422-33.

14 - TRAWINSKI, A. La cisticercosi degli animali e nell'uomo con particolare refe. rimento alla locallizazione cerebrale dei cisticechi. Zooprofllassi, 12(8):577-82, 1957.

Recebido para publicação em 10-3-77 Aprovado para publicaçäo em 3-8-77 